\title{
Overview of the Role of Cell Wall DUF642 Proteins in Plant Development
}

\author{
José Erik Cruz-Valderrama ${ }^{1}$, Ximena Gómez-Maqueo ${ }^{1}$, Alexis Salazar-Iribe ${ }^{1}{ }^{\mathbb{D}}$, \\ Esther Zúñiga-Sánchez ${ }^{1}$, Alejandra Hernández-Barrera ${ }^{1}{ }^{\mathbb{D}}$, Elsa Quezada-Rodríguez ${ }^{1}{ }^{\mathbb{D}}$ \\ and Alicia Gamboa-deBuen ${ }^{2, *}$ \\ 1 Instituto de Ecología, Universidad Nacional Autónoma de México. Mexico City 04510, Mexico \\ 2 Universidad Nacional Autónoma de México, Mexico City 04510, Mexico \\ * Correspondence: agamboa@ecologia.unam.mx
}

Received: 30 May 2019; Accepted: 4 July 2019; Published: 6 July 2019

check for updates

\begin{abstract}
The DUF642 protein family is found exclusively in spermatophytes and is represented by 10 genes in Arabidopsis and in most of the 24 plant species analyzed to date. Even though the primary structure of DUF642 proteins is highly conserved in different spermatophyte species, studies of their expression patterns in Arabidopsis have shown that the spatial-temporal expression pattern for each gene is specific and consistent with the phenotypes of the mutant plants studied so far. Additionally, the regulation of DUF642 gene expression by hormones and environmental stimuli was specific for each gene, showing both up- and down-regulation depending of the analyzed tissue and the intensity or duration of the stimuli. These expression patterns suggest that the DUF642 genes are involved throughout the development and growth of plants. In general, changes in the expression patterns of DUF642 genes can be related to changes in pectin methyl esterase activity and/or to changes in the degree of methyl-esterified homogalacturonans during plant development in different cell types. Thus, the regulation of pectin methyl esterases mediated by DUF642 genes could contribute to the regulation of the cell wall properties during plant growth.
\end{abstract}

Keywords: DUF642 family; homogalacturonans; plant cell wall; plant development; pectins

\section{Introduction}

Plant cell walls are dynamic compartments whose composition and chemical structure vary during plant development in response to environmental signals. Cell walls are composed of three layers: the middle lamella, and the primary and secondary cell walls. Primary cell wall deposition continues through cell growth and expansion. It is a very complex and dynamic structure composed mainly of three types of polysaccharides: cellulose, hemicelluloses, and pectins. Cellulose microfibrils and hemicelluloses constitute a network with structural proteins that are embedded in a gel-like matrix of pectins. Localization of different classes of polysaccharides within the cell wall appears to depend on species, organ, tissue, and cell type, and the pectin network is temporally and spatially regulated during plant development. Alterations of the cell wall structure and changes in properties during plant development are mainly the result of protein activities. Enzymatic activity and protein interactions respond to developmental and environmental signals and tightly regulate the complex and dynamic structure of plant cell walls.

In terrestrial plants, the chemical structure of homogalacturonans (HGs), a type of pectin that is comprised of chains of $\alpha-1,4$-galacturonic acid, is modified by de-methyl-esterification processes during plant development by pectin methyl esterases, and pectin methyl esterase inhibitory proteins regulate the degree of HGs' esterification of the cell wall in different cell types. Consequently, cell or tissue-specific function could be influenced by the HGs' status [1]. An increase in complexity in 
the regulation of HGs' esterification status through plant evolution has been described including a diversification of the gene families involved either in pectin synthesis or in pectin modification $[2,3]$. The shift from an aquatic to a terrestrial environment constitutes a milestone in the complexity of pectin regulation. In the algae Chara, cell growth is a result of a calcium pectate cycle that does not involve enzymatic activities [4]. Charophytes are the closest related group to land plants, thus, this enzyme-less mechanism could be still present in terrestrial plants [5].

The DUF642 protein family is found exclusively in spermatophytes and is involved in regulating HGs esterification. The DUF642 family was first described in apoplast proteomes of rosette leaves in Arabidopsis thaliana (Arabidopsis) by Boudart et al. [6] and subsequently in cell wall proteomes from different tissues and plant species from both dicotyledons and monocotyledons [7,8]. This multigene family is represented by 10 genes in Arabidopsis as well as in other plant species [9]. DUF642 proteins contain two DUF642 domains (PF04642) that present two conserved motifs NGXFEXXP and CGPVXD, determined as the family signature. A phylogenetic analysis revealed four clades of orthologous genes for all spermatophytes (Clades A, B, C, and D). After the divergence of gymnosperms and angiosperms, a duplication of Clade A occurred, producing two subclades (A1 and A2), and a subsequent duplication occurred after the divergence of monocotyledons and eudicotyledons [9].

The DUF642 proteins are encoded by genes that contain three exons. The first exon encodes a signal peptide, and the other two exons encode the DUF642 domains. Proteomic and cellular localization studies of the Clade A proteins indicated they were located primarily in the cell wall $[6,10]$. However, the protein encoded by $A t 3 g 08030$ was located in the nuclear pore, probably because this gene has an alternative first exon edition so one of the possible encoded protein lacks the signal peptide. The proteins in Clades B, C, and D have a GPI-anchor site at the carboxyl terminus and were detected in cell membrane proteomes [11].

The interactions of the DUF642 proteins with polysaccharides and cell wall enzymes have been demonstrated in vitro. The protein encoded by At3g08030 (Clade A2) interacted specifically with cellulose [11]. The proteins encoded by At4g32460/BDX and At5g11420 (Clade A1) interacted with the catalytic domain of a pectin methyl esterase (PME) [12]. In two transgenic Arabidopsis lines overexpressing BDX the PME activity increased in the seeds, seedlings, and the apical meristems, but no changes in PME activity were detected in the leaves [13]. PME activity was higher in the seeds of both overexpressing lines than it was in the control seeds during germination [13,14]. PME activity was also higher in seedlings, stems, leaves, and fruits in Arabidopsis plants overexpressing the VqDUF642 gene (Clade A1) of Vitis quinquangularis [15]. The leaves of Arabidopsis plants overexpressing the AhDGR2 gene (Clade A1) of Amaranthus hypochondriacus showed a decrease in PME activity, whereas an increase in PME activity was detected in the roots [16]. The phenotypes of all the Clade A1 protein mutants in Arabidopsis have been established. The At5g25460/dgr 2 mutant had a shorter root and smaller rosette leaves than the wild-type [17]. No alterations in the phenotypes of the At5g11420 and At1g80240/dgr1 mutants compared with the wild-type have been described. The At4g32460/bdx mutants had shorter siliques, seeds with altered development, and longer hypocotyl than the wild-type [18]. Among Arabidopsis Clade A2 mutants, the At2g41800/teb mutant is the only one for which a phenotype (longer hypocotyls) has been established [19]. No phenotypes have been established for the two Clade B genes At1g29980 and At2g34510, or the Clade D gene At5g14150.

\section{Expression Patterns of DUF642 Genes}

The expression patterns of the Clade A DUF642 genes have been studied in Arabidopsis plants transformed with constructs containing the putative promoter region fused to the reporter genes ER-GFP and GUS (Figure 1). Differential expression patterns were detected at different stages of plant development (Table 1). 
A

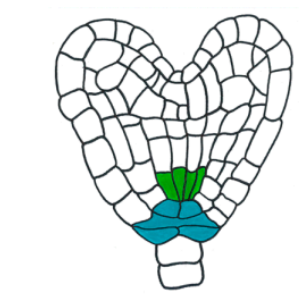

C

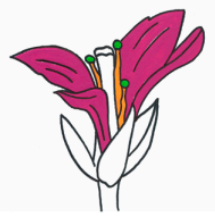

B

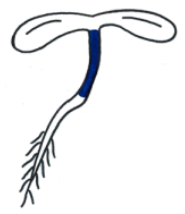

D

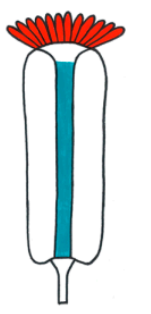

E

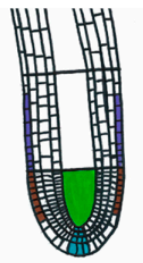

At4g32460 (BDX)

At3g08030

At5g25460 (DGR2)

$B D X$ and TEB

$B D X$ and $A t 3 g 08030$

$B D X$ and $A t 5 g 11420$

BDX, At5g11420,

TEB and At3g08030

$B D X, A t 5 g 11420, D G R 2$

TEB and At $3 g 08030$

Figure 1. Expression patterns of the DUF642 genes described to date using reporter genes during Arabidopsis plant development.

In Arabidopsis during embryonic development, BDX and At3g08030 were expressed from the heart stage onwards. In the late heart stage, At3g08030 was expressed in the quiescent center and in the columella cells, while BDX was expressed in the vascular tissue (Figure S1) [13].

During seedling development in Arabidopsis, BDX, At5g11420, DGR2, TEB, and At3g08030 were expressed in hypocotyls and $B D X$ and $D G R 2$ were also expressed in cotyledons, but no expression was detected for At5g11420, TEB, and At3g08030 [13,17,20]. In hypocotyls, specific expression of BDX, At5g11420, At3g08030, and TEB in the epidermal cells was determined by confocal microscopy. DGR1 and At2g34510 expression was detected specifically in hypocotyls grown under shade conditions [21]. Transcriptomic studies in Brassica rapa indicated that three orthologous genes of BDX, At5g11420, and DGR2 were expressed in hypocotyls [20].

The expression patterns of only DGR1, BDX, and DGR2 have been studied in leaves of Arabidopsis. $B D X$ expression was localized in the vascular tissue, $D G R 2$ expression was located in the leaf primordium, and DGR1 expression was not detected in the leaves $[13,17]$.

In flowers of Arabidopsis, $B D X$ was expressed in petals, vascular tissue of the filament, anther, and stigmatic papilla. At5g11420 was expressed in petals and abscission zones of floral whorls, TEB was expressed only in stigmatic papilla, and At3g08030 was expressed in the replum of androecium and epidermis of the filaments of stamens $[13,18]$ (Figure S1).

In Arabidopsis, DGR1, BDX, At5g11420, DGR2, TEB, and At3g08030 expression was detected in the primary root. BDX, At5g11420, DGR2, TEB, and At3g08030 were expressed in epidermal cells of the meristematic region. $B D X$ also was expressed in vascular tissue and $A t 3 g 08030$ was expressed in the quiescent center and in columella $[13,17,18]$ (Figure S1). These expression patterns were similar to those found during embryonic development.

During development of the lateral roots, BDX and At3g08030 expression was detected from stage II onwards, when cell proliferation begins (Figure 2). Further, at the moment of radicle protrusion, At5g11420 and TEB expression was detected in the epidermal cells that surround the radicle protrusion zone. The expression patterns of DGR1 and DGR2 during this process have not been determined.

The expression patterns of the Clade A DUF642 genes were altered by plant hormones (Table 1 and Table S1). For example, auxins and gibberellins increased the expression levels of BDX and TEB during Arabidopsis seed germination [22]. Exogenous auxins and gibberellins also altered the expression pattern of $B D X$ by promoting its expression in cortex cells in addition to vascular tissue of Arabidopsis. The expression pattern of $A t 3 g 08030$ was not altered by the addition of auxins [13]. 
Table 1. Expression profiles of the DUF642 genes detected in distinct tissues/organs and species. DUF642 genes are grouped by clades as reported by Vázquez-Lobo et al. (2012) [9] and using the locus tag of Arabidopsis as a reference for gene grouping.

\begin{tabular}{|c|c|c|c|c|}
\hline Clade & Gene Name & Species & Expressed in Tissue/Organ & Reference \\
\hline A1 & At1g80240 & Arabidopsis & Petal & [23] \\
\hline A1 & GRMZM2G027683 & Zea mays & Embryo & [24] \\
\hline A1 & $\begin{array}{l}\text { OSNPB_040494600 } \\
\text { Orthologous to }\end{array}$ & Oryza sativa & $\begin{array}{l}\text { Floral buds, flowers, mature seed, } \\
\text { milk grains, roots before flowering }\end{array}$ & [25] \\
\hline A1 & $\begin{array}{l}\text { At4g32460 } \\
\text { Orthologous to }\end{array}$ & Brassica rapa & Hypocotyl epidermal cells & [21] \\
\hline A1 & At4g32460 & Cannabis sativa & Stem (apical section) & [26] \\
\hline A1 & $\begin{array}{l}\text { OSNPB_020205200 } \\
\text { Orthologous to }\end{array}$ & Oryza sativa & $\begin{array}{c}\text { Floral buds, flowers, mature seed, } \\
\text { milk grains }\end{array}$ & [25] \\
\hline A1 & At5g11420 & Brassica rapa & Hypocotyl epidermal cells & [21] \\
\hline A1 & At5g11420 & Arabidopsis & Petal & [23] \\
\hline A1 & At5g11420 & Arabidopsis & Root (cortex) & [27] \\
\hline A1 & OSNPB_010611000 & Oryza sativa & $\begin{array}{l}\text { Floral buds, flowers, mature seed, } \\
\text { milk grains, roots before flowering } \\
\text { Floral buds, milk grains, roots }\end{array}$ & [25] \\
\hline A1 & $\begin{array}{l}\text { OSNPB_040494800 } \\
\text { Orthologous to }\end{array}$ & Oryza sativa & before flowering & [25] \\
\hline A1 & At5g25460 & $\begin{array}{l}\text { Brassica rapa } \\
\text { Amaranthus }\end{array}$ & Hypocotyl epidermal cells & [21] \\
\hline A1 & AhDGR2 & $\begin{array}{l}\text { hypochondriacus } \\
\text { var. Revancha }\end{array}$ & $\begin{array}{c}\text { Panicle, axillary bud, young stem, } \\
\text { and young leaf }\end{array}$ & [16] \\
\hline A1 & GRMZM2G051571 & Zea mays & Seed & [24] \\
\hline A1 & $\begin{array}{l}\text { GRMZM2G034985 } \\
\text { Orthologous to }\end{array}$ & Zea mays & $\begin{array}{l}\text { Seed, shoot, root, SAM, ear, tassel, } \\
\text { cob, silk, anthers, ovule }\end{array}$ & [24] \\
\hline A1 & At5g25460 & Cannabis sativa & Stem (apical section) & [26] \\
\hline A1 & At5g25460 & Arabidopsis & Root (cortex) & [27] \\
\hline $\begin{array}{l}\mathrm{A} 2 \\
\mathrm{~A} 2\end{array}$ & $\begin{array}{l}\text { similar to } \\
\text { At3g08030 } \\
\text { At3g08030 }\end{array}$ & $\begin{array}{l}\text { Brassica rapa } \\
\text { Arabidopsis }\end{array}$ & $\begin{array}{l}\text { Hypocotyl inner tissue cells } \\
\text { Root (cortex/hair cell) }\end{array}$ & $\begin{array}{l}{[21]} \\
{[27]}\end{array}$ \\
\hline A2 & At2g41800 & Arabidopsis & Carpel & [23] \\
\hline A2 & OSNPB_030807700 & Oryza sativa & $\begin{array}{l}\text { Floral buds, flowers, mature seed, } \\
\text { milk grains, roots before flowering }\end{array}$ & [25] \\
\hline A2 & At2g41810 & Brassica rapa & Hypocotyl epidermal cells & [21] \\
\hline B & $\begin{array}{l}\text { Orthologous to } \\
\text { At1g29980 }\end{array}$ & Brassica rapa & $\begin{array}{l}\text { Hypocotyl inner tissue cells } \\
\text { Floral buds, flowers, leaves before }\end{array}$ & [21] \\
\hline B & OSNPB_010756600 & Oryza sativa & $\begin{array}{l}\text { grains, roots before flowering } \\
\text { Seed shoot root SAM ear tassel }\end{array}$ & [25] \\
\hline B & GRMZM2G324705 & Zea mays & cob, silk, anthers, ovule & [24] \\
\hline
\end{tabular}




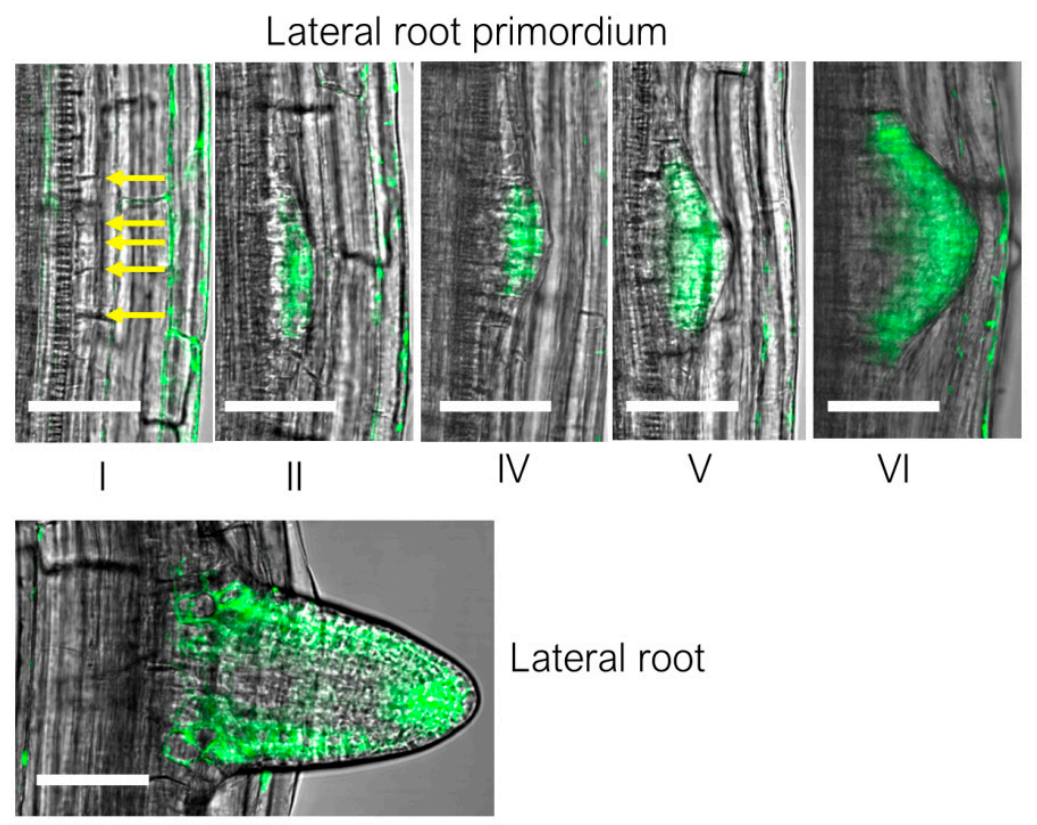

Figure 2. Expression patterns of At3g08030 during lateral root development. The Arabidopsis pAt3g08030::ER-GFP-transgenic plants were obtained as described in Salazar-Iribe et al. [19]. Roman numerals indicate the developmental stages of the lateral root initiation process. The images are all section images. $n=8-10$ roots for each developmental stage. Scale bars $=20 \mu \mathrm{m}$.

\section{Subcellular Localization of DUF642 Proteins}

DUF642 proteins are very abundant in cell wall proteomes from different tissues and plant species [7,8]. The At3g08030 protein has been found in all Arabidopsis cell wall proteomes reported so far. TEB and DGR1 were found in the proteomes of cell suspension cultures, whereas DGR2 was found in the proteomes of cell suspension cultures, hypocotyls, and mature stems. The At5g11420 protein was present in the proteomes of apoplast, hypocotyls, and mature stems, whereas BDX was found only in the mature stem cell wall proteome [28]. The localization of BDX and TEB in the Arabidopsis cell wall was confirmed by confocal microscopy in hypocotyl cells $[18,19]$. The VqDUF642 protein was localized in the cell wall of tobacco epidermal cells [15] and peach PpDU642 (TEB) was localized in the cell wall and extracellular space during a transient expression in tomato fruit [29].

Studies carried out to determine the subcellular localization of BDX in epidermal root cells of Arabidopsis suggested that it was localized intracellularly, probably in Golgi, and then relocated to the cell wall when the plants were subjected to abiotic $(\mathrm{NaCl})$ or biotic (nematodes) stress stimuli [30] (Figure S2). TEB is highly expressed during cell division prior to cytokinesis. In Arabidopsis, the synchronization of mitosis in primary root cells treated with hydroxyurea [31] confirmed that TEB was localized intracellularly during mitosis, and was located in the cell wall until the end of the process (Figure 3). These results suggest that BDX and TEB are located transiently in the cell wall in response to endogenous or exogenous stimuli. Finally, polar localization of TEB in the cell wall of radicular hair was determined during its elongation, suggesting the formation of domains with an accumulation of these proteins within the cell walls [19]. 

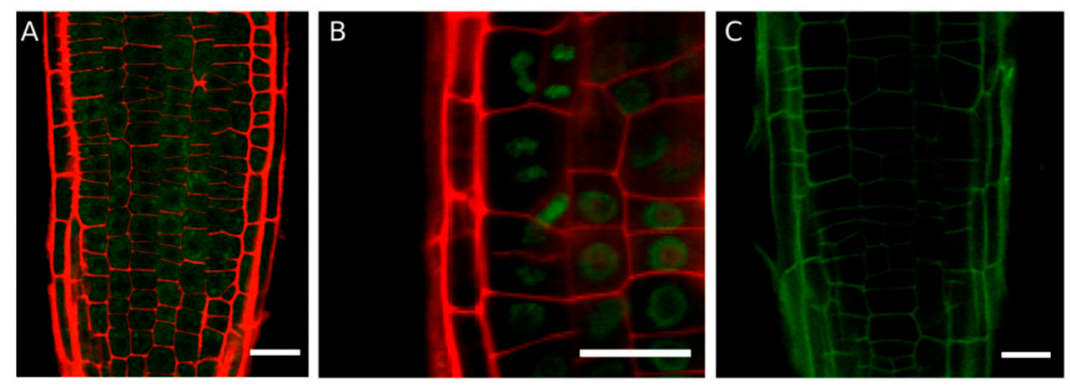

Figure 3. Subcellular localization of the TEB protein in meristematic root cells synchronized with hydroxyurea. (A) Arabidopsis $p T E B:: T E B-G F P$ seedlings were treated with hydroxyurea for $16 \mathrm{~h}$, and a diffuse pattern of GFP in meristematic cells of the cortex was observed. The cell wall was stained with propidium iodide (red). (B) After $18 \mathrm{~h}$ of hydroxyurea treatment, GFP was detected as a ring surrounding the nucleus in the cortex cells. (C) TEB was located in the cell wall after $19 \mathrm{~h}$ of hydroxyurea treatment. Hydroxyurea stops DNA synthesis and after 16-17 h most of the cells are at the G2/M transition and at 18-20 h cytokinesis occurs according to Cools et al. [31]. Seedlings were sown in MS medium and transferred on day 6 to MS medium with hydroxyurea for 16-20 h. The images are all section images. Scale bars $=20 \mu \mathrm{m}$. The Arabidopsis transgenic plants were obtained as described in Salazar-Iribe et al. [19].

\section{Function of DUF642 Proteins in Plant Development}

The expression patterns of DUF642 genes suggest they are involved throughout the development and growth of plants. In general, changes in the expression patterns of DUF642 genes can be related directly to PME activity $[13,15,16,19]$. The leaves of Arabidopsis lines overexpressing AHDGR2 had low PME activity, and this was reflected in alterations in the pattern of de-methyl-esterified HGs in the cell walls $[16,19,32]$.

\subsection{Seed Development}

In Arabidopsis, BDX, At5g11420, TEB, and At3g08030 were expressed during embryo development (Table 1 and Table S1), and the localized expression during development indicated differential expression in different cell types (Figure 1). However, the $b d x-1$, At2g11420, and teb-1 mutants did not show alterations in gene expression during embryo development.

During endosperm development, BDX was the only DUF642 gene reported at four days after pollination [33]. Of the $d g r 1, b d x-1, A t 5 g 11420, d g r 2$, and teb-1 mutants studied during seed development, only the $b d x-1$ mutant showed alterations, producing misshapen seeds with changes in the folding of the embryo. The endosperm and seed coat exert physical restrictions during elongation and folding of the embryo [34], with the walls of the endosperm adjacent to the embryo showing a decrease in the degree of HGs esterification. In the $b d x-1$ mutant, a lower signal of de-methyl-esterified HGs compared with the wild-type was detected in this region. Alterations in the degree of esterification can cause greater rigidity of the cell wall of endosperm cells, thereby generating a physical restriction in the development of the embryo and compromising the subsequent survival of the seedling [32].

The accumulation of DUF642 gene transcripts has also been reported in mature seeds. Germination pre-treatments such as priming, which improve germination performance, can induce the expression of these genes. An important increase in the expression of the orthologous gene of At3g08030 was reported in seeds from Brassica oleracea subjected to an osmopriming treatment [35]. In Arabidopsis, Ceiba aesculifolia, and Wigandia urens seeds, the expression of At3g08030 increased in response to osmopriming treatment and decreased when the seeds were subjected to controlled deterioration [36]. In a study carried out with Arabidopsis vps 29 mutant seeds (VPS29 rearrangement complex), which had a lower germination index, the abundance of $A t 3 g 08030$ and $A t 1 g 29980$ increased while that of At5g11420 and DGR2 decreased [37]. Functional studies of $A t 3 g 08030$ loss of function mutants could reveal if this gene has a role in promoting seed longevity. 
After seed maturation, the expression of At5g11420, DGR2, At3g08030, and At1g29980 increased in after-ripened seeds (Table S1). These changes in expression may be related to changes in the biochemical machinery that are required to modify the architecture of the cell wall of the embryo, the endosperm, and the seed coat during germination.

\subsection{Germination}

During the germination process of barley, Brassica, and Arabidopsis seeds, progressive differential expression of several DUF642 genes took place (Table S1). The expression levels of Clade A1 genes (BDX, At5g11420 and DGR2) and At3g14310, which codes for PME3, increased after $6 \mathrm{~h}$ of seed imbibition. The expression of the Clade A2 gene, TEB, increased between 8 and $12 \mathrm{~h}$, and At3g08030 expression was detected in the mature seeds and during the entire imbibition process (Figure S3).

The lines overexpressing BDX, At5g11420, and DGR2 showed a decrease in the onset of germination, especially in the timing of the testa rupture, compared with the wild-type seeds [13] (Figure S3). The increase in total PME activity during seed germination in the overexpressing plants may be related to the early testa rupture described previously [14]. Early testa rupture also was observed in tomato seeds from tomato plants overexpressing VqDUF642 [15]. These results indicate that the Clade A1 genes have the same function during germination.

\subsection{Hypocotyls}

Under control growth conditions (long photoperiod), the Arabidopsis $b d x-1$ and teb-1 mutant lines had longer hypocotyls because of longer cell length compared with the wild-type, whereas the overexpressing lines produced shorter hypocotyls. The hypocotyls of the $b d x-1$ and teb-1 mutants had a higher signal for methyl-esterified HGs. Additionally, the $b d x-1$ mutant accumulated more auxins in the epidermal cells than the wild-type [18]. During cell elongation in the hypocotyl, auxin signaling and cell wall modifications of epidermal cells were actively involved $[38,39]$. The accumulation of auxins in hypocotyl epidermal cells during cell elongation was facilitated by PIN transporters. In the $b d x-1$ mutant, a change in the localization of PIN1 transporters was detected, possibly because of the degree of HGs esterification, as has been described for other tissues [40]. The $b d x$ and teb mutants showed an altered hypocotyl phenotype, suggesting DUF642 genes may be involved in regulating hypocotyl elongation during seedling development [41].

\subsection{Leaves}

The expression of DGR1, BDX, At5g11420, DGR2, TEB, At2g41810, At3g08030, At2g34510, and At5g14150 was detected in rosette leaves of mature Arabidopsis plants close to flowering (Table S1). The $d g r 1, b d x-1$, and teb-1 mutants showed no alterations in the development of rosette leaves. The dgr2 mutant had a smaller rosette, explained by its expression in leaf primordia [17]. The lines overexpressing BDX, At5g11420, and TEB showed no visible alterations in the leaves or in the size of the rosette $[13,19]$. No differences were found in the leaves of Arabidopsis plants overexpressing AhDGR2 or tomato plants overexpressing VqDUF642 [15,16]. The mechanisms that control leaf origin and growth are complex, because of the phenotypic plasticity that is present in leaves as a mechanism for adaptation to different environments [42]. The complexity of the regulation of leaf size and morphology, and the lack of alterations in the leaves of mutant lines suggest the DUF642 genes are functionally redundant in leaves.

\subsection{Reproductive Structures}

During flower development in Arabidopsis, the DUF642 genes studied to date showed differential expression patterns, although the expression of only two genes have been detected in carpel, stamens, and petals. BDX is the only DUF642 gene that has been detected in the anthers of stamens. The $b d x-1$ mutant line showed morphological alterations of the pollen grain that altered its viability. The in vitro germination of the pollen tube was lower in the $b d x-1$ mutant pollen grains that in the wild-type. 
The structural and functional alterations of the pollen grains in the $b d x-1$ mutant could be caused by changes in the accumulation of auxins during the late stages of anther development (Figure 4). Similar alterations in pollen morphology have been described in mutants related to the auxin signaling pathway, including auxin synthesis and transport [43].
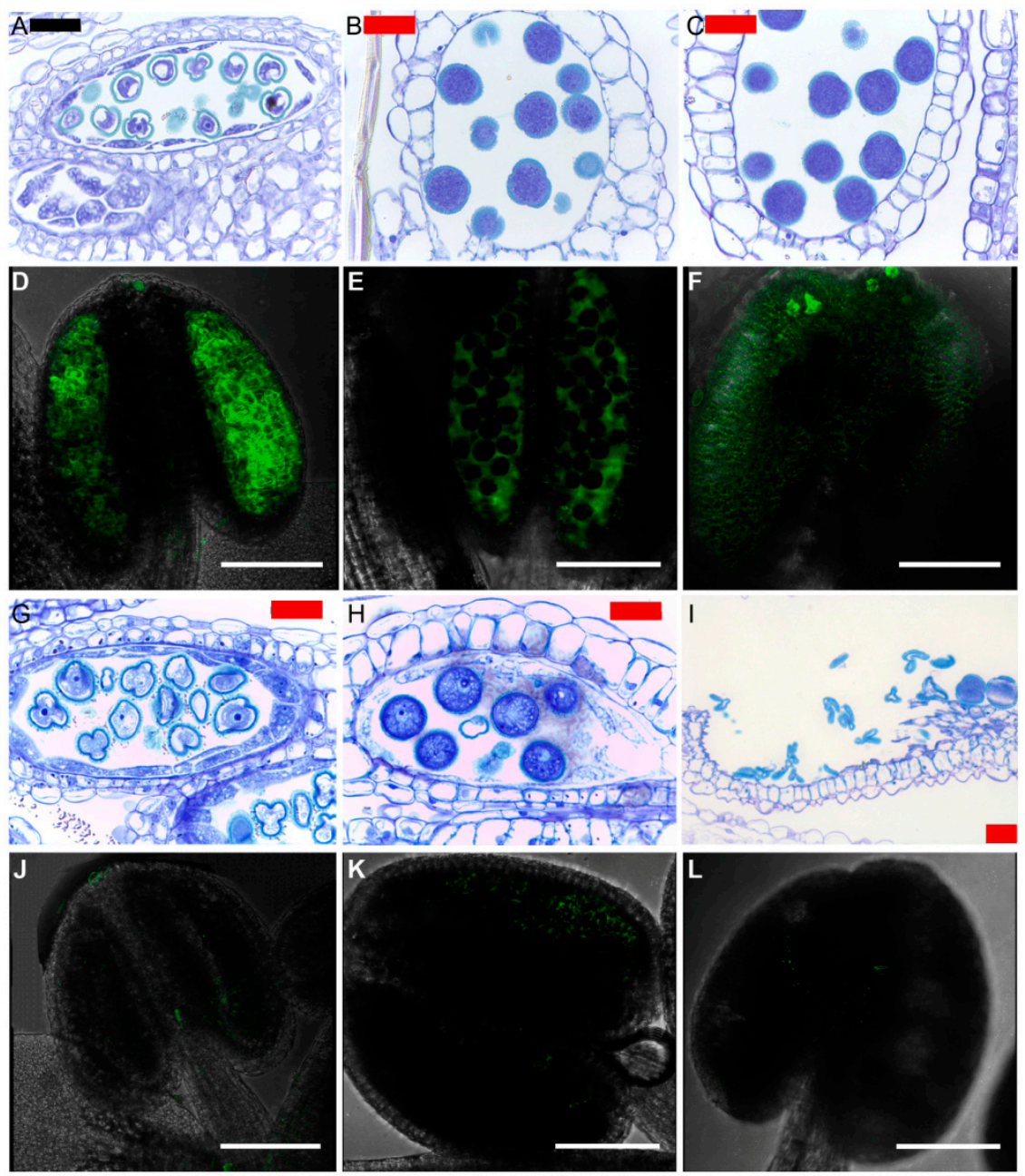

Figure 4. Pollen grain development and auxin accumulation in anthers of flowers from wild-type and $b d x$-1 mutant Arabidopsis plants. Normal pollen grain development in wild-type (wt) flowers. (A) Anthers from 7-8 stage flower. (B) Anthers from 11-12 stage flower. (C) Anthers from 13 stage flower. GFP detection of auxins in anthers from wt/DR5 flowers. (D) Anthers from 7-8 stage flower. (E) Anthers from 11-12 stage flower. (F) Anthers from 13 stage flower. Throughout the development of the anther there is an important accumulation of auxins. Pollen grain development in $b d x-1 / D R 5$ flowers. (G) Anthers from 7-8 stage flower. (H) Anthers from 11-12 stage flower. (I) Anthers from 13 stage flower. The development of pollen grains is altered; at the 11-12 stage, diffuse cytoplasm is observed and, at stage 13, some pollen grains have collapsed. GFP detection of auxins in anthers from $b d x-1 / D R 5$ flowers. (J) Anthers from 7-8 stage flower. (K) Anthers from 11-12 stage flower. (L) Fertilized flowers at stage 13. Throughout the development of the anther there is almost no accumulation of auxins. The Arabidopsis transgenic plants were obtained as described in Cruz-Valderrama et al. [32]. Sections: 1-2 $\mu \mathrm{m}$. Staining was with toluidine blue. Red bar $=20 \mu \mathrm{m}$, Black bar $=10 \mu \mathrm{m} . \mathrm{n}=8-10$ plants for each line. White bar $=100 \mu \mathrm{m} . \mathrm{n}=5-9$ anthers from flowers from different plants.

\subsection{Fruits}

Studies of DUF642 gene expression and gene function during fruit development are very scarce. Of the Arabidopsis mutants studied, only $b d x-1$ showed a fruit phenotype with shorter siliques and 
lower seed production than wild-type plants. In the genus Brassica, DGR2 is the only gene that has been detected in transcriptomes of siliques, specifically in the shells of the pods [44].

\subsection{Roots}

The expression of DGR1, BDX, At5g11420, DGR2, and TEB has been detected in primary roots of Arabidopsis. All these genes were expressed in the epidermal cells of the meristematic zone, except $D G R 2$, which was expressed in the elongation zone. The dgr2 mutant was the only one that presented a short root phenotype [17]. Overexpression of $A h D G R 2$ in Arabidopsis produced longer roots [16], which is understandable given that DGR2 was expressed in the meristematic zone where the cells begin to expand and the rate of cell division is reduced.

The $b d x-1, A t 5 g 11420$, and teb-1 mutants showed no alterations in the development of lateral roots. BDX, At3g08030, At5g11420, and TEB all had similar expression patterns throughout the development of lateral roots, which suggested there could be a functional redundancy that would explain the lack of altered phenotypes for these mutants.

Roots interact with microorganisms in the soil, and are particularly susceptible to pathogen attacks. Roots also are central in the perception of nutrient concentrations and other elements like heavy metals in the substrate where plants develop. The modification and restructuring of the cell wall in roots actively participate in the response to different types of stresses. Therefore, the participation of DUF642 genes in the remodeling of the cell wall can be relevant in all these processes. Changes in the expression of DUF642 genes in response to biotic and abiotic stresses have been described in various plant species (Table S2). However, very few functional studies are available related to the particular role of DUF642 genes in response to stress.

\section{Biotic Factors}

$D G R 2$ is negatively regulated in Arabidopsis plants during infection by the bacterium Ralstonia solanacerum [45]. The expression of At1g29980 and At3g08030 is induced by infection with Rhodococcus fascians [46]. At3g08030 also is highly expressed in response to infection by Agrobacterium tumefaciens [47].

The abundance of the DUF642 protein encoded by At3g08030, which has two isoforms with different isoelectric points, was reduced significantly in the cell wall proteome of Arabidopsis suspension cells treated with chitosan, an elicitor that mimics a fungal infection [48]. Infection with the Penicillium strain Pc4 in post-harvest grapes increased the abundance of two isoforms of the At5g11420 orthologous protein, probably because of post-translational modification [49]. In apoplastic proteomes of maize roots (Zea mays) infected with the symbiont species Trichoderma virens, a DUF642 protein was detected 5 days after inoculation. Modification and degradation of root cell walls are essential for colonization to take place [50]. Infection of Arabidopsis plants with the phytopathogenic fungus Botrytis cinerea reduced the expression of $A t 5 g 11420$ and At5g25460 [51].

The overexpression of VqDUF642 in tomato plants reduced the susceptibility to B. cinerea infection in both mature and immature fruits. Overexpression of this gene modified the expression of some pathogen response genes such as SIPR1, SIPR2, SIPR3, and SIPR4 whose expression increased at $48 \mathrm{~h}$ post-infection. In transgenic Thompson grape plants, overexpression of VqDUF642 promoted increased resistance to B. cinerea and induced resistance to the fungus Erysiphe necator, which causes oidium of vines. The leaves of the overexpressing plants infected with E. necator showed a less severe infection than the wild-type at $48 \mathrm{~h}$ post-infection. In addition, the expression levels of the pathogen-response genes $V v P R 1, V v P R 2, V v P R 3$, and $V v P R 4$ increased drastically at 48- and 96-h post-infection in transgenic seedlings compared with in the wild-type [15].

In Arabidopsis, transcriptomic induction during early inoculation with the knot-nematode Meloidogyne incognita revealed up-regulation of $A t 1 g 29980$ [52]. BDX and TEB expression were also highly induced by M. incognita early inoculation. The cell wall localization of BDX and TEB in the epidermal cells of primary roots was induced by M. incognita. Early inoculation with Nacobus aberrans, a nematode that cannot infect Arabidopsis, did not alter the expression of these two genes [30]. 
A comparative analysis of available Arabidopsis flower transcriptomes showed that changes in the expression patterns of flower-specific defense genes were critical in pathogen resistance. According to this study, the expression of $B D X$ and DGR2 was positively regulated in petals compared with in senescent leaves, in stage 15 of the flower. At this stage, an increase in the expression of the biotic stress response genes also occurred [53].

\section{Abiotic Factors}

The regulation of the DUF642 genes by transcription factors in response to aluminum stress has been reported. Aluminum stress has been studied extensively in aluminum-resistant plants. In particular, Oryza sativa (rice) is a cultivated crop plant that is resistant to aluminum, and the signaling pathway associated with its resistance has been studied widely. The $\mathrm{Al}$ resistance transcription factor 1 gene $(A R T 1)$ is central to the aluminum response, and it regulates an increase in the expression of the DUF642 gene Os04g049490 (orthologous to At5g11420) [54]. Os04g049490 was also regulated by the SENSITIVE TO ALUMINUM RHIZOTOXICITY gene (STAR1), which plays a fundamental role in aluminum resistance in rice roots [55]. In the O. sativa indica IR64 cultivar treated with aluminum, Os04g41750 (orthologous to At5g11420) expression was up-regulated, whereas no change in its expression was detected in O. sativa cv. Azucena, which is more sensitive to aluminum [56]. Plants in the genus Stylosanthes have high tolerance to toxicity by the aluminum ion, and expression of the orthologous DUF642 gene Os04g0494900 increased in the roots of the Reyan 2 genotype in response to aluminum treatment [57]. A comparison between the transcriptomes of two Citrus species with different aluminum tolerances suggested that the process of HGs de-esterification in the cell wall of the root cells played an important role in resistance to aluminum. In C. sinensis, which is resistant to aluminum, four genes related to this process and a DUF642 gene, an ortholog of DGR2, were up-regulated [58]. In NtSTOP-1-RNAi tobacco plants that showed a decrease in the expression of the SENSITIVE TO PROTON RHIZOTOXICITY gene (STOP1), the expression of Nt6860 (orthologous to At5g11420) decreased, as has been described for At5g11420 in the Arabidopsis art-1 mutant [59].

In Medicago sativa plants exposed to cadmium, the amount of the protein orthologous to the Arabidopsis protein, DGR2, decreased [60]. The exposure of Populus $\times$ canadensis plants to high doses of zinc promoted the decrease in the expression of POPTR_0001s27110 (orthologous to At3g08030) [61].

Ultraviolet radiation (UV-B) generates an imbalance in the production of reactive oxygen species. Thus, it is used to study the effects of oxidative stress on plants. In the mutant ggt1 of the protein GAMMA-GLUTAMYL TRANSFERASE ISOFORM 1(GGT1), involved in the redox balance, the proteins DGR2 and PECTIN METHYL ESTERASE3 (At3g14310) are very abundant in both the mutant and in the wt of Arabidopsis plants exposed to UV-B [62].

In the salinity-resistant plant Manihot esculenta Crantz (Cassava), RknMes02_00171 and RknMes02_00443, which are orthologs of BDX and At5g11420 respectively, were among the 40 most highly expressed genes during $\mathrm{NaCl}$ treatment [63]. AhDGR2 was significantly induced in Amaranthus hypochondriacus (grain amaranth), which is also resistant to high doses of salt. However, when $A h D G R 2$ was overexpressed in Arabidopsis, the plants showed hypersensitivity to increasing $\mathrm{NaCl}$ concentrations, as shown by shorter root length, smaller and slightly chlorotic rosettes, as well as considerably reduced germination rates [16].

The expression levels of $A t 2 g 34510$ and At5g11420 increased in Arabidopsis plants subjected to drought stress, although their expression levels were not altered by treatment with abscisic acid [64]. The increase in $A t 2 g 34510$ expression induced by drought was corroborated in a study that tested the stress response in natural populations of Arabidopsis [65]. In Eucalyptus calmadulensis, the expression of Eucgr.C02812 (orthologous to At5g11420) was also found to decrease in plants exposed to drought [66].

\section{Conclusions}

The DUF642 proteins are highly conserved, which may be related to their specific interactions with cell wall polysaccharides and proteins in different cell types. The At3g08030-encoded protein 
interacts in vitro with cellulose, a polysaccharide that has an important role in plant development [9]. However, there are still no functional studies that confirm this interaction. BDX and At5g11420 interact in vitro with a PME [12]. Studies in different plant species suggest that their function could be related to the regulation of HGs modification throughout plant development. The functional studies carried out to date are consistent with this hypothesis. For instance, in almost all plant tissues where DUF642 gene overexpression has been induced, there was an increase in the total PME activity. Furthermore, the increase in methyl-esterified HGs in the endosperm during embryo folding and in hypocotyl epidermal cells in the DUF642 mutants is consistent with the corresponding phenotype. However, a direct interaction of DUF642 proteins with PMEs needs to be established using different experimental approaches. Several proteomic studies have indicated the presence of two isoforms of the same DUF642 protein, suggesting these proteins undergo post-translational modifications that may be related to differential interactions within the cell wall $[29,60,61]$.

The different functions of DUF642 genes during development can be determined by the specific spatial-temporal expression pattern for each gene. The differential response to hormones also may participate in this process. BDX is the only DUF642 gene expressed in the endosperm during seed development. This specific expression may explain the misshapen-seeds phenotype in the $b d x-1$ mutant. Similarly, the expression of DGR2 in the root elongation zone may explain the short root phenotype exclusive of the $d g r 2$ mutant. It is possible that there is functional redundancy during embryo development as well as during the development and emergence of the lateral root, processes in which the same temporal-spatial pattern of at least two DUF642 genes was detected in Arabidopsis. $B D X, A t 5 g 11420, T E B$, and At3g08030 are expressed in the meristematic zone of the primary root, but the $b d x$ and teb mutants do not show an altered root phenotype. BDX was located intracellularly in the epidermal cells of the primary root and relocated to the cell wall in response to biotic and abiotic stresses. Roots interact with different organisms in the soil and are subjected to multiple perturbations in the environment, such as decreases in the availability of water and increases in toxic ions. These interactions can alter the expression of some DUF642 genes. In the response to fungal infection, the overexpression of VqDUF642 increased resistance to the pathogen, although the expression other DUF642 genes decreased in response to infection. These results suggest that the DUF642 genes participate broadly in plant responses to environmental factors and not solely in the root developmental process.

The primary structure of DUF642 proteins is highly conserved in different spermatophyte species. However, studies of their expression patterns in Arabidopsis showed that the spatial-temporal expression pattern for each gene was specific and consistent with the phenotypes of the mutant plants studied so far. The regulation of DUF642 gene expression by hormones and environmental stimuli also was specific for each gene. Functional studies of the DUF642 genes in different plant species are needed to determine the relevance of the DUF642 family in the evolution of terrestrial plants.

Supplementary Materials: Supplementary materials can be found at http://www.mdpi.com/1422-0067/20/13/ 3333/s1. Figure S1. At3g08030 expression during Arabidopsis thaliana development using pAt3g08030::ER-GFP plants; Figure S2. At5g11420 expression during Arabidopsis thaliana development using pAt5g11420::ER-GFP plants; Figure S3. At4g32460/BDX, At5g25460/DGR2, At5g11420, At3g14310/PME3, At2g41800/TEB and At3g08030 expression during seed germination; Figure S4. Subcellular localization of BDX in Arabidopsis thaliana primary roots under salinity stress conditions using $p B D X:: B D X-G F P$ plants. Table S1. Transcriptomic evidence of DUF642 genes expression during specific developmental stages and/or in response to diverse environmental stimuli. Table S2. Transcriptomic evidence of DUF642 genes expression in response to diverse environmental stimuli.

Author Contributions: J.E.C.V., X.G.-M., and A.G.-d.; participated in the conceptualization and in the review and edition of the manuscript. J.E.C.V.; A.S.-I., E.Z.-S., A.H.-B., and E.Q.-R. carried out the molecular genetic studies. J.E.C.-V., X.G.-M., A.S.-I., E.Z.-S., and A.G.-d. participated in the original draft preparation. Funding was provided to A.G.-d. All authors read and approved the final manuscript.

Funding: This research was funded by Programa de Apoyo a Proyectos de Investigación e Innovación Tecnológica, Universidad Nacional Autónoma de México grant number IN203218- X.G.-M received a fellowship from Dirección General de Asuntos del Personal Académico, Universidad Nacional Autónoma de México. 
Acknowledgments: We thank K. Jiménez for assistance on Confocal studies and M. Guemez for the artwork (Figure 1). We thank M. Biswas, from Edanz Group (www.edanzediting.com/ac) for editing a draft of this manuscript.

Conflicts of Interest: No conflict of interest is declared.

\section{References}

1. De Lorenzo, G.; Ferrari, S.; Giovannoni, M.; Mattei, B.; Cervone, F. Cell wall traits that influence plant development, immunity, and bioconversion. Plant J. 2019, 97, 134-147. [CrossRef] [PubMed]

2. Yang, Z.L.; Liu, H.J.; Wang, X.R.; Zeng, Q.Y. Molecular evolution and expression divergence of the Populus polygalacturonase supergene family shed light on the evolution of increasingly complex organs in plants. New Phytol. 2013, 197, 1353-1365. [CrossRef] [PubMed]

3. McCarthy, T.W.; Der, J.P.; Honaas, L.A.; Claude, W.D.; Anderson, C.T. Phylogenetic analysis of pectin-related gene families in Physcomitrella patens and nine other plant species yields evolutionary insights into cell walls. BMC Plant Biol. 2014, 14, 79. [CrossRef] [PubMed]

4. Proseus, T.E.; Boyer, J.S. Calcium deprivation disrupts enlargement of Chara corallina cells: Further evidence for the calcium pectate cycle. J. Exp. Bot. 2012, 63, 3953-3958. [CrossRef] [PubMed]

5. Boyer, J.S. Enzyme-less growth in Chara and terrestrial plants. Front. Plant Sci. 2016, 7, 866. [CrossRef] [PubMed]

6. Boudart, G.; Jamet, E.; Rossignol, M.; Lafitte, C.; Borderies, G.; Jauneau, A.; Esquerré-Tugayé, M.-T.; Pont-Lezica, R. Cell wall proteins in apoplastic fluids of Arabidopsis thaliana rosettes: Identification by mass spectrometry and bioinformatics. Proteomics 2005, 5, 212-221. [CrossRef] [PubMed]

7. Jamet, E.; Canut, H.; Boudart, G.; Pont-Lezica, R.F. Cell wall proteins: A new insight through proteomics. Trends Plant Sci. 2006, 11, 33-39. [CrossRef]

8. Calderan-Rodrigues, M.J.; Guimarães Fonseca, J.; de Moraes, F.E.; Vaz Setem, L.; Carmanhanis Begossi, A.; Labate, C.A. Plant cell wall proteomics: A focus on monocot species, Brachypodium distachyon, Saccharum spp. and Oryza sativa. Int. J. Mol. Sci. 2019, 20, 1975. [CrossRef]

9. Vázquez-Lobo, A.; Roujol, D.; Zuñiga-Sánchez, E.; Albenne, C.; Piñero, D.; Gamboa de Buen, A.; Jamet, E. The highly conserved spermatophyte cell wall DUF642 protein family: Phylogeny and first evidence of interaction with cell wall polysaccharides in vitro. Mol. Phylogenet. Evol. 2012, 63, 510-520. [CrossRef]

10. Feiz, L.; Irshad, M.; Pont-Lezica, R.F.; Canut, H.; Jamet, E. Evaluation of cell wall preparations for proteomics: A new procedure for purifying cell walls from Arabidopsis hypocotyls. Plant Methods 2006, 2, 10. [CrossRef]

11. Borner, G.H.H.; Lilley, K.S.; Stevens, T.J.; Dupree, P. Identification of glycosylphosphatidylinositol-anchored proteins in Arabidopsis. A proteomic and genomic analysis. Plant Physiol. 2003, 132, 568-577. [CrossRef]

12. Zúñiga-Sánchez, E.; Gamboa-de Buen, A. The two DUF642 At5g11420 and At4g32460-encoded proteins interact in vitro with the AtPME3 catalytic domain. In Protein Interactions; Cai, J., Wang, R., Eds.; IntechOpen: London, UK, 2012.

13. Zúñiga-Sánchez, E.; Soriano, D.; Martínez-Barajas, E.; Orozco-Segovia, A.; Gamboa-deBuen, A. BIIDXI, the At4g32460 DUF642 gene, is involved in pectin methyl esterase regulation during Arabidopsis thaliana seed germination and plant development. BMC Plant Biol. 2014, 14, 338. [CrossRef] [PubMed]

14. Müller, K.; Levesque-Tremblay, G.; Bartels, S.; Weitbrecht, K.; Wormit, A.; Usadel, B.; Haughn, G.; Kermode, A.R. Demethylesterification of cell wall pectins in Arabidopsis plays a role in seed germination. Plant Physiol. 2013, 161, 305-316. [CrossRef] [PubMed]

15. Xie, X.; Wang, Y. VqDUF642, a gene isolated from the Chinese grape Vitis quinquangularis, is involved in berry development and pathogen resistance. Planta 2016, 244, 1075-1094. [CrossRef] [PubMed]

16. Palmeros-Suárez, P.A.; Massange-Sánchez, J.A.; Sánchez-Segura, L.; Martínez-Gallardo, N.A.; Rangel, E.E.; Gómez-Leyva, J.F.; Délano-Frier, J.P. AhDGR2, an amaranth abiotic stress-induced DUF642 protein gene, modifies cell wall structure and composition and causes salt and ABA hyper-sensibility in transgenic Arabidopsis. Planta 2017, 245, 623-640. [CrossRef] [PubMed]

17. Gao, Y.; Badejo, A.A.; Sawa, Y.; Ishikawa, T. Analysis of two L-galactono-1, 4-lactone-responsive genes with complementary expression during the development of Arabidopsis thaliana. Plant Cell Physiol. 2012, 53, 592-601. [CrossRef] [PubMed] 
18. Salazar-Iribe, A.; Cruz-Valderrama, J.E.; Jímenez-Durán, K.; Gómez-Maqueo, X.; Gamboa-deBuen, A. BIIDXI, a DUF642 cell wall protein, is involved in hypocotyl growth via auxin efflux. J. Plant Physiol. 2018, 231, 105-109. [CrossRef]

19. Salazar-Iribe, A.; Agredano-Moreno, L.T.; Zúñiga-Sánchez, E.; Jiménez-Garcia, L.F.; Gamboa-deBuen, A. The cell wall DUF642 At2g41800 (TEB) protein is involved in hypocotyl cell elongation. Plant Sci. 2016, 253, 206-214. [CrossRef]

20. Kohnen, M.V.; Schmid-Siegert, E.; Trevisan, M.; Petrolati, L.A.; Sénéchal, F.; Müller-Moulé, P.; Fankhauser, C. Neighbor detection induces organ-specific transcriptomes, revealing patterns underlying hypocotyl-specific growth. Plant Cell 2016, 28, 2889-2904. [CrossRef]

21. Procko, C.; Burko, Y.; Jaillais, Y.; Ljung, K.; Long, J.A.; Chory, J. The epidermis coordinates auxin-induced stem growth in response to shade. Genes Dev. 2016, 30, 1529-1541. [CrossRef]

22. Ogawa, M.; Hanada, A.; Yamauchi, Y.; Kuwahara, A.; Kamiya, Y.; Yamaguchi, S. Gibberellin biosynthesis and response during Arabidopsis seed germination. Plant Cell 2003, 15, 1591-1604. [CrossRef] [PubMed]

23. Wellmer, F.; Riechmann, J.L.; Alves-Ferreira, M.; Meyerowitz, E.M. Genome-wide analysis of spatial gene expression in Arabidopsis flowers. Plant Cell 2004, 16, 1314-1326. [CrossRef] [PubMed]

24. Chen, J.; Zeng, B.; Zhang, M.; Xie, S.; Wang, G.; Hauck, A.; Lai, J. Dynamic transcriptome landscape of maize embryo and endosperm development. Plant Physiol. 2014, 166, 252-264. [CrossRef] [PubMed]

25. Wang, H.; Niu, Q.W.; Wu, H.W.; Liu, J.; Ye, J.; Yu, N.; Chua, N.H. Analysis of non-coding transcriptome in rice and maize uncovers roles of conserved lnc RNA s associated with agriculture traits. Plant J. 2015, 84, 404-416. [CrossRef]

26. De Pauw, M.A.; Vidmar, J.J.; Collins, J.; Bennett, R.A.; Deyholos, M.K. Microarray analysis of bast fibre producing tissues of Cannabis sativa identifies transcripts associated with conserved and specialised processes of secondary wall development. Funct. Plant Biol. 2007, 34, 737-749. [CrossRef]

27. Shulse, C.N.; Cole, B.J.; Ciobanu, D.; Lin, J.; Yoshinaga, Y.; Gouran, M.; Turco, G.M.; Zhu, Y.; O’Malley, R.C.; Brady, S.M.; et al. High-throughput single-cell transcriptome profiling of plant cell types. Cell Rep. 2019, 27, 2241-2247. [CrossRef] [PubMed]

28. Minic, Z.; Jamet, E.; Négroni, L.; Arsene der Garabedian, P.; Zivy, M.; Jouanin, L. A sub-proteome of Arabidopsis thaliana mature stems trapped on Concanavalin A is enriched in cell wall glycoside hydrolases. J. Exp. Bot. 2007, 58, 2503-2512. [CrossRef]

29. Bustamante, C.A.; Budde, C.O.; Borsani, J.; Lombardo, V.A.; Lauxmann, M.A.; Andreo, C.S.; Lara, M.V.; Drincovich, M.F. Heat treatment of peach fruit: Modifications in the extracellular compartment and identification of novel extracellular proteins. Plant Physiol. Biochem. 2012, 60, 35-45. [CrossRef]

30. Salazar-Iribe, A.; Zúñiga-Sánchez, E.; Mejía, E.Z.; Gamboa-deBuen, A. Cell wall localization of two DUF642 proteins, BIIDXI and TEEBE, during Meloidogyne incognita early inoculation. Plant Pathol. J. 2017, 33, 614.

31. Cools, T.; Iantcheva, A.; Maes, S.; Van den Daele, H.; De Veylder, L. A replication stress-induced synchronization method for Arabidopsis thaliana root meristems. Plant J. 2010, 64, 705-714. [CrossRef]

32. Cruz-Valderrama, J.E.; Jiménez-Durán, K.; Zúñiga-Sánchez, E.; Salazar-Iribe, A.; Márquez-Guzmán, J.; Gamboa-deBuen, A. Degree of pectin methyl esterification in endosperm cell walls is involved in embryo bending in Arabidopsis thaliana. Biochem. Biophys. Res. Commun. 2018, 495, 639-645. [CrossRef] [PubMed]

33. Day, R.C.; Herridge, R.P.; Ambrose, B.A.; Macknight, R.C. Transcriptome analysis of proliferating Arabidopsis endosperm reveals biological implications for the control of syncytial division, cytokinin signaling, and gene expression regulation. Plant Physiol. 2008, 148, 1964-1984. [CrossRef] [PubMed]

34. Fourquin, C.; Beauzamy, L.; Chamot, S.; Creff, A.; Goodrich, J.; Boudaoud, A.; Ingram, G. Mechanical stress mediated by both endosperm softening and embryo growth underlies endosperm elimination in Arabidopsis seeds. Development 2016, 143, 3300-3305. [CrossRef] [PubMed]

35. Soeda, Y.; Konings, M.C.; Vorst, O.; van Houwelingen, A.M.; Stoopen, G.M.; Maliepaard, C.A.; van der Geest, A.H. Gene expression programs during Brassica oleracea seed maturation, osmopriming, and germination are indicators of progression of the germination process and the stress tolerance level. Plant Physiol. 2005, 137, 354-368. [CrossRef] [PubMed]

36. Garza-Caligaris, L.E.; Avendaño-Vázquez, A.O.; Alvarado-López, S.; Zúñiga-Sánchez, E.; Orozco-Segovia, A.; Pérez-Ruíz, R.V.; Gamboa-deBuen, A. At3g08030 transcript: A molecular marker of seed ageing. Ann. Bot. 2012, 110, 1253-1260. [CrossRef] [PubMed] 
37. Durand, T.C.; Cueff, G.; Godin, B.; Valot, B.; Clément, G.; Gaude, T.; Rajjou, L. Combined proteomic and metabolomic profiling of the Arabidopsis thaliana vps29 mutant reveals pleiotropic functions of the retromer in seed development. Int. J. Mol. Sci. 2019, 20, 362. [CrossRef] [PubMed]

38. Zheng, Z.; Guo, Y.; Novák, O.; Chen, W.; Ljung, K.; Noel, J.P.; Chory, J. Local auxin metabolism regulates environment-induced hypocotyl elongation. Nat. Plants 2006, 2, 16025. [CrossRef] [PubMed]

39. Derbyshire, P.; McCann, M.C.; Roberts, K. Restricted cell elongation in Arabidopsis hypocotyls is associated with a reduced average pectin esterification level. BMC Plant Biol. 2007, 7, 31. [CrossRef] [PubMed]

40. Braybrook, S.A.; Peaucelle, A. Mechano-chemical aspects of organ formation in Arabidopsis thaliana: The relationship between auxin and pectin. PLOS ONE 2013, 8, e57813. [CrossRef]

41. Irshad, M.; Canut, H.; Borderies, G.; Pont-Lezica, R.; Jamet, E. A new picture of cell wall protein dynamics in elongating cells of Arabidopsis thaliana: Confirmed actors and newcomers. BMC Plant Biol. 2008, 8, 94. [CrossRef]

42. Horiguchi, G.; Ferjani, A.; Fujikura, U.; Tsukaya, H. Coordination of cell proliferation and cell expansion in the control of leaf size in Arabidopsis thaliana. J. Plant Res. 2006, 119, 37-42. [CrossRef] [PubMed]

43. Cardarelli, M.; Cecchetti, V. Auxin polar transport in stamen formation and development: How many actors? Front. Plant Sci. 2014, 5, 333. [CrossRef] [PubMed]

44. Jaradat, M.R.; Ruegger, M.; Bowling, A.; Butler, H.; Cutler, A.J. A comprehensive transcriptome analysis of silique development and dehiscence in Arabidopsis and Brassica integrating genotypic, interspecies and developmental comparisons. GM Crops Food 2014, 5, 302-320. [CrossRef] [PubMed]

45. Hu, J.; Barlet, X.; Deslandes, L.; Hirsch, J.; Feng, D.X.; Somssich, I.; Marco, Y. Transcriptional responses of Arabidopsis thaliana during wilt disease caused by the soil-borne phytopathogenic bacterium, Ralstonia solanacearum. PLoS ONE 2008, 3, e2589. [CrossRef] [PubMed]

46. Depuydt, S.; Trenkamp, S.; Fernie, A.R.; Elftieh, S.; Renou, J.P.; Vuylsteke, M.; Holsters, M.; Vereecke, D. An integrated genomics approach to define niche establishment by Rhodococcus fascians. Plant Physiol. 2009, 149, 1366-1386. [CrossRef] [PubMed]

47. Lee, C.W.; Efetova, M.; Engelmann, J.C.; Kramell, R.; Wasternack, C.; Ludwig-Müller, J.; Hedrich, R.; Deeken, R. Agrobacterium tumefaciens promotes tumor induction by modulating pathogen defense in Arabidopsis thaliana. Plant Cell 2009, 21, 2948-2962. [CrossRef] [PubMed]

48. Ndimba, B.K.; Chivasa, S.; Hamilton, J.M.; Simon, W.J.; Slabas, A.R. Proteomic analysis of changes in the extracellular matrix of Arabidopsis cell suspension cultures induced by fungal elicitors. Proteomics 2003, 3 , 1047-1059. [CrossRef]

49. Lorenzini, M.; Mainente, F.; Zapparoli, G.; Cecconi, D.; Simonato, B. Post-harvest proteomics of grapes infected by Penicillium during withering to produce Amarone wine. Food Chem. 2016, 199, 639-647. [CrossRef]

50. Nogueira-Lopez, G.; Greenwood, D.R.; Middleditch, M.; Winefield, C.; Eaton, C.; Steyaert, J.M.; Mendoza-Mendoza, A. The apoplastic secretome of Trichoderma virens during interaction with maize roots shows an inhibition of plant defense and scavenging oxidative stress secreted proteins. Front. Plant Sci. 2018, 9, 409. [CrossRef]

51. Coolen, S.; Proietti, S.; Hickman, R.; Davila Olivas, N.H.; Huang, P.P.; Van Verk, M.C.; Van Loon, J.J. Transcriptome dynamics of Arabidopsis during sequential biotic and abiotic stresses. Plant J. 2016, 86, 249-267. [CrossRef]

52. Barcalá, M.; García, A.; Cabrera, J.; Casson, S.; Lindsey, K.; Favery, B.; García-Casado, G.; Solano, R.; Fenoll, C.; Escobar, C. Early transcriptomic events in microdissected Arabidopsis nematode-induced giant cells. Plant J. 2010, 61, 698-712. [CrossRef] [PubMed]

53. Ederli, L.; Dawe, A.; Pasqualini, S.; Quaglia, M.; Xiong, L.; Gehring, C. Arabidopsis flower specific defense gene expression patterns affect resistance to pathogens. Front. Plant Sci. 2015, 6, 79. [CrossRef] [PubMed]

54. Tsutsui, T.; Yamaji, N.; Huang, C.F.; Motoyama, R.; Nagamura, Y.; Ma, J.J. Comparative genome-wide transcriptional analysis of Al-responsive genes reveals novel $\mathrm{Al}$ tolerance mechanisms in rice. PLoS ONE 2012, 7, e48197. [CrossRef]

55. Tsutsui, T.; Yamaji, N.; Feng, J.M. Identification of a cis-acting element of ART1, a C2H2-type zinc-finger transcription factor for aluminum tolerance in rice. Plant Physiol. 2011, 156, 925-993. [CrossRef] [PubMed] 
56. Arbelaez, J.D.; Maron, L.G.; Jobe, T.O.; Pineros, M.A.; Famoso, A.N.; Rebelo, A.R.; Singh, N.; Ma, Q.; Fei, Z.; Kochian, L.V.; et al. ALUMINUM RESISTANCE TRANSCRIPTION FACTOR 1 (ART 1) contributes to natural variation in aluminum resistance in diverse genetic backgrounds of rice (O. sativa). Plant Direct. 2007, 1, e00014. [CrossRef] [PubMed]

57. Jiang, C.; Liu, L.; Li, X.; Han, R.; Wei, Y.; Yu, Y. Insights into aluminum-tolerance pathways in Stylosanthes as revealed by RNA-Seq analysis. Sci. Rep. 2018, 8, 6072. [CrossRef]

58. Guo, P.; Qi, Y.P.; Yang, L.T.; Lai, N.W.; Ye, X.; Yang, Y.; Chen, L.S. Root adaptive responses to aluminum-treatment revealed by RNA-Seq in two Citrus species with different aluminum-tolerance. Front. Plant Sci. 2017, 8, 330. [CrossRef]

59. Ito, H.; Kobayashi, Y.; Yamamoto, Y.Y.; Koyama, H. Characterization of NtSTOP1-regulating genes in tobacco under aluminum stress. Soil Sci. Plant Nutr. 2019, 65, 1-8. [CrossRef]

60. Gutsch, A.; Zouaghi, S.; Renaut, J.; Cuypers, A.; Hausman, J.F.; Sergean, K. Changes in the proteome of Medicago sativa leaves in response to long-term cadmium exposure using a cell-wall targeted approach. Int. J. Mol. Sci. 2018, 19, 2498. [CrossRef]

61. Ariani, A.; Di Baccio, D.; Romeo, S.; Lombardi, L.; Andreucci, A.; Lux, A. RNA Sequencing of Populus $x$ canadensis roots identifies key molecular mechanisms underlying physiological adaption to excess zinc. PLoS ONE 2015, 10, e0117571. [CrossRef]

62. Trentin, A.R.; Pivato, M.; Mehdi, S.M.M.; Barnabas, L.E.; Giaretta, S.; Fabrega-Prats, M.; Prasad, D.; Arrigoni, G.; Masi, A. Proteome readjustments in the apoplastic space of Arabidopsis thaliana ggt1 mutant leaves exposed to UV-B radiation. Front. Plant Sci. 2015, 6, 128. [CrossRef] [PubMed]

63. Patanun, O.; Ueda, M.; Itouga, M.; Kato, Y.; Utsumi, Y.; Matsui, A.; Tanaka, M.; Utsumi, C.; Sakakibara, H.; Yoshida, M.; et al. The histone deacetylase inhibitor suberoylanilide hydroxamic acid alleviates salinity stress in Cassava. Front. Plant Sci. 2017, 7, 2039. [CrossRef] [PubMed]

64. Huang, D.; Wu, W.; Abrams, S.R.; Cutler, A.J. The relationship of drought-related gene expression in Arabidopsis thaliana to hormonal and environmental factors. J. Exp. Bot. 2008, 59, 2991-3007. [CrossRef] [PubMed]

65. Des Marais, D.L.; McKay, J.K.; Richards, J.H.; Sen, S.; Wayne, T.; Juenger, T.E. Physiological genomics of response to soil drying in diverse Arabidopsis accessions. Plant Cell 2012, 24, 893-914. [CrossRef] [PubMed]

66. Thumma, B.R.; Sharma, N.; Southerton, S.G. Transcriptome sequencing of Eucalyptus camaldulensis seedlings subjected to water stress reveals functional single nucleotide polymorphisms and genes under selection. BMC Genom. 2012, 13, 364. [CrossRef] [PubMed]

(C) 2019 by the authors. Licensee MDPI, Basel, Switzerland. This article is an open access article distributed under the terms and conditions of the Creative Commons Attribution (CC BY) license (http://creativecommons.org/licenses/by/4.0/). 